\title{
ILUSTRASI CERPEN RENJAYA SIAHAAN PADA KORAN ANALISA
}

\author{
Nahanda Tinambunan $^{1 *}$, R. Triyanto ${ }^{2 *}$, Adek Cerah Kurnia Azis ${ }^{3 *}$ \\ Program Studi Pendidikan Seni Rupa Jurusan Seni Rupa Fakultas Bahasa dan Seni \\ Universitas Negeri Medan \\ Jl. Willem Iskandar Pasar V Medan Estate, Kec. Percut Sei Tuan, Kab. Deli Serdang, Kode Pos 20371 \\ Sumatera Utara. Indonesia \\ Email:nahandabunan@gmail.com,triyantoraden75@gmail.com,adek_peros@yahoo.com
}

\begin{abstract}
Abstrak
Cat air merupakan media yang sangat sulit untuk digunakan dibandingkan media cat lainnya. Pewarnaan yang dilakukan dengan melapisi warna dengan warna lainnya cenderung membuat kertas mudah rusak dan terkadang tidak sesuai dengan warna yang diharapkan. Kesalahan juga kerap terjadi saat mencampur air dengan cat air. Kadang konsistensinya masih terlalu pekat dan bahkan kadang terlalu encer sehingga dalam pengaplikasiannya harus penuh pertimbangan dan kehati-hatian. Penelitian ini bertujuan untuk mengetahui perbedaan tentang teknik menggambar ilustrasi yang diterapkan Renjaya Siahaan dengan teknik aquarel dalam menggunakan media cat air. Metode yang digunakan dalam penelitian adalah deskriptif kualitatif. Pengambilan sampel dalam penelitian ini menggunakan teknik purposive sampling, yaitu 10 karya ilustrasi cerpen di Koran Analisa tahun 2018-2019. Pengambilan data dilakukan dengan melakukan studi pustaka, wawancara dan observasi. Hasil penelitian menyimpulkan bahwa teknik yang diterapkan Renjaya Siahaan dalam mengaplikasikan cat pada permukaan kertas cenderung bersifat plakat. Proses pembuatan gambar ilustrasi Renjaya Siahaan dimulai dengan membaca cerpen yang akan di ilustrasikan, perenungan dan observasi terkait objek apa saja yang akan digambarkan. Selanjutnya setelah ide diperoleh dilanjutkan dengan pembuatan sketsa, pemberian warna dasar, menambah kesan gelap terang dan tahap finishing. Teknik yang diterapkan Renjaya Siahaan lebih boros cat dan memerlukan lebih banyak waktu dalam proses pengerjaannya dibandingkan dengan penggunaan cat air dengan teknik aquarel dimana lebih efektif dan efisien dalam hal meminimalisir waktu pengerjaan dan penggunaan material.
\end{abstract}

Kata Kunci: ilustrasi cerpen, renjaya siahaan, analisa.

\begin{abstract}
Watercolor is a medium that is very difficult to use compared to other paint media. Coloring that is done by overlaying the colors with other colors tends to make the paper easily damaged and sometimes doesn't match the expected color. Mistakes also often occur when mixing water with watercolors. Sometimes the consistency is still too thick and sometimes too runny so that the application must be full of consideration and caution. This study aims to determine the difference between the illustration drawing technique applied by Renjaya Siahaan and the aquarel technique in using watercolor media. The method used in this research is descriptive qualitative. Sampling in this study used a purposive sampling technique, namely 10 short story illustrations in Analisa Newspaper Daily in the year of 2018 2019. Data were collected by conducting literature studies, interviews and observations. The results of the study concluded that the technique applied by Renjaya Siahaan in applying paint to the surface of the paper tended to be opaque. The process of making a Renjaya Siahaan illustration image begins with reading a short story that will be illustrated, contemplating and observing what objects will be depicted. Furthermore, after the idea is obtained, it is continued with making a sketch, giving basic colors, adding a dark and light impression and the finishing stage. The technique applied by Renjaya Siahaan is more wasteful of paint and requires more time in the processing process compared to the use of watercolor with aquarel technique which is more effective and efficient in minimizing processing time and material usage.
\end{abstract}

Keywords: cerpen illustration, renjaya siahaan, analisa.

\section{PENDAHULUAN}

Antara ilustrator dan pengarang merupakan suatu kolaborasi yang utuh dalam satu kesatuan, sementara Ilustrator dapat mengekspresikan gagasannya melalui bahasa visual menurut gaya dan keahliannya masingmasing. Teknik pengolahan alat dan bahan adalah caracara khusus yang digunakan seorang Ilustrator dalam membuat suatu karya ilustrasi. Sehingga dapat 


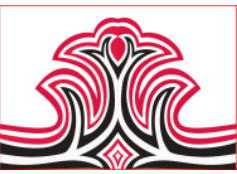

dikatakan bahwa setiap Ilustrator mempunyai cara tersendiri dalam mengeksplorasikan alat dan bahan yang digunakan.

Renjaya Siahaan seorang Ilustrator cerpen pada Harian Analisa menerapkan teknik tersendiri dalam menggunakan media cat air. Teknik plakat yang biasa digunakan pada media cat acrylic, cat minyak maupun gouache diterapkan oleh Renjaya menggunakan media cat air di tiap gambar ilustrasi cerpen pada Harian Analisa.

Penggunaan alat, bahan dan waktu pengerjaan sangat perlu diperhitungkan dalam menggunakan media cat air. Teknik plakat biasanya membutuhkan waktu lebih lama pengerjaannya dibandingkan teknik aquarel. Hal ini disebabkan cat yang disapukan dengan tebal lebih lama kering, belum lagi apabila ingin menimpa warna sebelumnya dengan warna lain akan memerlukan waktu yang lama menunggu warna pertama kering terlebih dahulu. Selain itu pula, penggunaan cat air yang bersifat plakat lebih boros cat. Hal ini tentu saja menjadi pertimbangan dalam pemberian harga terhadap sebuah gambar ilustrasi disebabkan penggunaan material yang lebih banyak daripada dikerjakan dengan teknik aquarel yang cenderung menggunakan cat yang sedikit.

Berdasarkan pengamatan tersebut maka muncul ketertarikan peneliti untuk mempelajari dan mengamati tentang proses penerapan teknik dalam pembuatan ilustrasi cerpen karya Renjaya Siahaan menggunakan cat air.

\section{KAJIAN TEORI}

\section{Pengertian Ilustrasi Cerpen}

Secara etimologis, istilah ilustrasi diambil dari bahasa Inggris, illustration dengan bentuk kata kerjanya to illustrate, berasal dari bahasa latin illustrare yang berarti membuat terang (Salam, 2017: 2). Menurut Kusrianto (2007: 140) "Ilustrasi dikatakan sebagai seni gambar yang dipakai untuk memberi penjelasan atas suatu tujuan tertentu ataupun maksud tertentu dan penjelasan tersebut disampaikan secara visual". Sedangkan pengertian cerpen menurut Priyatni (2010: 126) "Cerpen adalah salah satu bentuk karya fiksi. Cerpen sesuai dengan namanya, memperlihatkan sifat yang serba pendek, baik peristiwa yang diungkapkan, isi cerita, jumlah pelaku dan jumlah kata yang digunakan".

Sehingga dapat disimpulkan bahwa ilustrasi cerpen merupakan representasi visual dari sebuah cerita fiksi yang bersifat pendek, untuk memperjelas isi dari cerita
Gorga : Jurnal Seni Rupa

Volume 10 Nomor 01 Januari-Juni 2021

p-ISSN: 2301-5942 | e-ISSN: 2580-2380

tersebut. Ilustrasi tersebut tidak lepas dengan apa yang disebut dengan istilah menggambar dimana pengertian menggambar adalah suatu kegiatan atau proses dalam menciptakan karya visual seni rupa dua dimensi. Seperti halnya menggoreskan pensil, krayon dan sebagainya di media berupa kertas, kanvas, dan lain lain (Halawa, 2020: 194).

\section{Teknik Ilustrasi Cat Air}

Menurut Maharsi (2016: 123-136) "secara garis besar terdapat dua media yang sering digunakan oleh para kreator ilustrasi, yaitu media kering atau dry media dan media basah atau wet media. Dry media berkaitan dengan menggambar (drawing). Sedangkan wet media merupakan topik dari melukis (painting). Contoh $d r y$ media yaitu charcoal, pastel, pensil warna, marker, pen (ballpoint). Kemudian contoh wet media yaitu cat air, cat poster, acrylic, dan aquarel pencil".

Cat air dibuat dengan pigmen warna yang dilarutkan dengan air dan ditorehkan pada media seperti kertas, kayu maupun kanvas dengan efek yang pada umumnya bersifat aquarel. Cat air memiliki karakteristik warna yang cerah dan bersih. Sehingga untuk mencapai warna yang diinginkan, cat air harus ditimpa secara berlapislapis. Teknik pengerjaannya, menurut Said (2016: 11) "Pewarnaan lukisan cat air dimulai dari warna paling terang hingga warna yang lebih gelap. Jika warna gelap dimulai lebih dahulu, efeknya akan kusam".

Berdasarkan pendapat di atas maka dapat disimpulkan bahwa teknik ilustrasi cat air merupakan bagian dari wet media. Cat air memiliki karakteristik warna yang cerah dan bersih dan terkesan bersifat aquarel. Dalam pengerjaannya, pewarnaan dimulai dengan memberi warna yang paling terang terlebih dahulu hingga ke warna yang lebih gelap.

\section{Bahan dan Alat Ilustrasi Cat Air}

Membuat gambar ilustrasi menggunakan teknik cat air, bahan yang digunakan diantaranya: air dan cat air. Kemudian alat yang biasa digunakan yaitu: kuas, palet, kertas khusus cat air, tisu, pensil dan penghapus. Kuas yang digunakan untuk membuat ilustrasi dengan cat air adalah yang berbulu halus dan terasa lembut jika dipegang dengan jari, karena cocok digunakan untuk bahan cat pengencer air. Kekuatan penyerapan kertas dapat diukur dari jenis dan jumlah gelatin atau kanji yang terkandung di dalam kertas. Kertas cat air tersedia terutama dalam tiga jenis permukaan, yaitu hot press, cold press dan rough.

\section{Tahapan Ilustrasi Cat Air 1). Tahap Pertama: Sketsa}


Hal pertama yang dilakukan adalah membuat sketsa kasar yang tidak terlalu detail. Biasanya menggunakan pensil jenis $H B$ agar garis yang dihasilkan tipis sehingga garis-garis pensil dapat tertutup oleh lapisan cat.

\section{2). Tahap Kedua: Pemberian Warna Dasar Background}

Pewarnaan dimulai dengan memberikan warna tipis di bagian background. Pencampuran cat dengan air dilakukan dengan persentase air lebih banyak dibandingkan cat. Dalam hal ini bidang yang akan diberi warna putih dibiarkan kosong menggunakan warna kertas.

\section{3). Tahap Ketiga: Mempertegas Bentuk Dasar}

Tahap ini cat dilukiskan dengan perbandingan lebih banyak air. Pembentukan objek-objek diciptakan dengan perbedaan intensitas warna dengan menampilkan gelap terang sehingga gambar tampak berdimensi. Batas-batas antara objek yang satu dengan objek lainnya menjadi hal yang perlu ditekankan dalam tahap ini. Sehingga diperoleh bentuk dan perkiraan penekanan kontras yang diberikan untuk menghasilkan komposisi yang menarik.

\section{4). Tahap Keempat: Memberikan Penekanan Warna}

Perbedaan intensitas warna memberi ilusi jarak dengan penekanan warna yang lebih kontras. Warna-warna pekat ditingkatkan pencampurannya dengan menggunakan lebih sedikit air. Dengan pemberian warna yang lebih pekat pada objek bagian foreground tampak batas antara objek-objek lebih jelas.

\section{5). Tahap Kelima: Finishing}

Dalam penyelesaiannya, bagian foreground dipertegas dengan detail yang sangat baik dibandingkan bagian lainnya. Penambahan detail bayangan mendukung gelap terang sehingga fokus pada lukisan terlihat. Pada bagian background warna-warna hanya diberi kesankesan tipis, hal ini bertujuan agar lukisan tampak dramatis dan memunculkan kesan kedalaman.

\section{Struktur Seni Rupa}

\section{1). Unsur-Unsur Seni Rupa}

Unsur-unsur seni rupa adalah segala hal yang secara umum terdapat pada setiap karya seni rupa sebagai elemen visual pembentuk karya secara keseluruhan. Hal dasar inilah yang harus dikuasai pelaku seni sebagai dasar atas kaidah-kaidah keseniannya. Unsur unsur tersebut antara lain: titik, garis, bidang, bentuk, warna, gelap terang, tekstur, ruang.
Gorga : Jurnal Seni Rupa

Volume 10 Nomor 01 Januari-Juni 2021

p-ISSN: 2301-5942 | e-ISSN: 2580-2380

\section{2). Prinsip-Prinsip Seni Rupa}

Menurut Sembiring (2014: 142) "Prinsip-prinsip seni adalah cara pengorganisasian unsur-unsur bentuk agar tampak padu dan harmonis. Penerapan prinsip-prinsip ini mempengaruhi konten ekspresif atau pesan dari hasil karya". Adapun prinsip-prinsip yang dimaksud yaitu: keselarasan, kesatuan, keseimbangan, aksentuasi, irama, proporsi

\section{Biodata Renjaya Siahaan}

Renjaya Siahaan merupakan seorang ilustrator cerpen di Koran Analisa. Renjaya lahir di Paindoan pada 28 Mei 1988. Ia merupakan alumni Pendidikan Seni Rupa di Universitas Negeri Medan angkatan tahun 2006. Semenjak tahun 2014 hingga sekarang, karya-karya Renjaya selalu menghiasi rubrik rebana dalam bentuk ilustrasi cerpen.

Ilustrasi-ilustrasi yang dihadirkan Renjaya merupakan ilustrasi menggunakan media cat air. Hasil gambar yang telah diselesaikan kemudian di-foto ataupun discan untuk selanjutnya dikirim ke redaksi Koran Analisa. Karya ilustrasinya kerap membuat decak kagum orang yang melihatnya. Selain penerapan unsurunsur dan prinsip seni rupa yang baik, teknik yang diterapkan pun tampak unik karena dikembangkan sesuai gayanya sendiri.

Teknik yang dipakai dalam membuat ilustrasi cerpen karya Renjaya Siahaan adalah campuran teknik aquarel dengan teknik plakat. Penggunaan cat yang tebal sering digunakan untuk membuat detail suatu objek sehingga tampak lebih kontras dengan gelap terang yang jelas.

\section{METODE PENELITIAN}

Penelitian ini dilaksanakan di Mieko Art School Jln. Iskandar Muda No. 282, Petisah Hulu, Kec. Medan Baru, Kota Medan, Sumatera Utara 20152. Dimana tempat ini Renjaya Siahaan sebagai guru pengajar sekaligus tempat membuat karya ilustrasi cerpen untuk Koran Analisa. Jumlah populasi sebanyak 86 karya yang diterbitkan sejak Januari 2018 sampai Oktober 2019. Penelitian ini menggunakan sampel penelitian purposive sampling, dengan total sampel 10 karya ilustrasi cerpen. Metode yang digunakan adalah metode analisis deskriptif kualitatif. Teknik pengumpulan data yang digunakan yaitu studi pustaka, observasi, wawancara dan dokumentasi. Instrumen penelitian yang digunakan yaitu human instrumen dimana peneliti sendiri sebagai instrumen utama. Teknik analisis data yang digunakan pada penelitian ini menggunakan model yang dikemukakan oleh Miles dan Huberman yang meliputi (a) reduksi data, (b) penyajian data, (c) penyimpulan. 


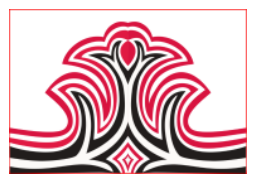

\section{HASIL DAN PEMBAHASAN}

1.Hasil

\section{1). Sampel 10 Karya Renjaya Siahaan}

Keunikan teknik yang diterapkan oleh Renjaya Siahaan pada gambar ilustrasi cerpen terletak pada penggunaan warna-warna yang tebal dan terkesan plakat. Proses pengerjaan dilakukan dengan tahapan yang terencana sebagai proses yang selalu mempertimbangkan kualitas pewarnaan objek-objek yang digarap secara detail.

Gambar Ilustrasi Renjaya Siahaan dibuat menggunakan media cat air dengan teknik plakat. Penggunaan media cat air yang bersifat plakat sangat jarang diterapkan kebanyakan Ilustrator. Teknik ini dikembangkan Renjaya Siahaan sebagai ciri khas dalam membuat gambar ilustrasi. Selain teknik, penggunaan warna yang cenderung glow in the dark atau menampilkan warna terang diantara warna gelap juga mendukung tampilan gambar ilustrasinya sehingga menarik perhatian orang yang melihatnya.

Hampir semua gambar ilustrasi yang menjadi subjek dalam penelitian ini dikerjakan Renjaya Siahaan menggunakan media cat air dengan menerapkan teknik yang sama. Sehingga penulis hanya perlu mengamati salah satu cara pembuatan gambar ilustrasi untuk mengetahui bagaimana teknik yang diterapkan Renjaya Siahaan dengan mengamati proses dan langkah kerjanya.

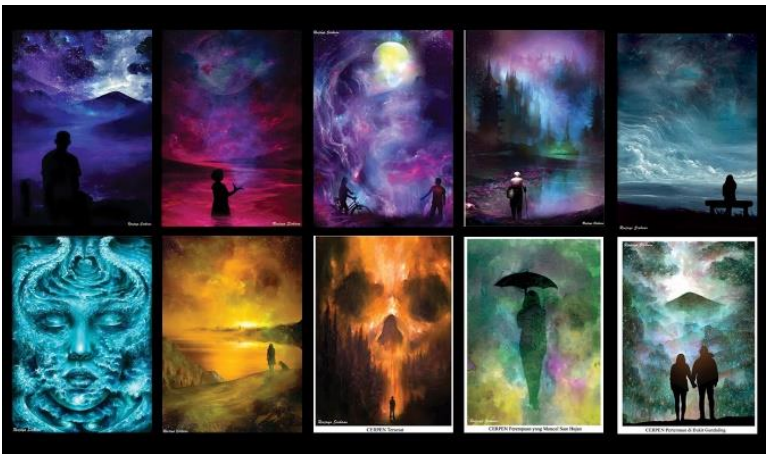

Gambar 1. 10 Sampel Ilustrasi Cerpen Renjaya Siahaan Pada Koran Analisa

(Siahaan, 2019)
Gorga : Jurnal Seni Rupa

Volume 10 Nomor 01 Januari-Juni 2021

p-ISSN: 2301-5942 | e-ISSN: 2580-2380

\section{2). Tahapan Pembuatan Ilustrasi Cerpen Renjaya Siahaan}

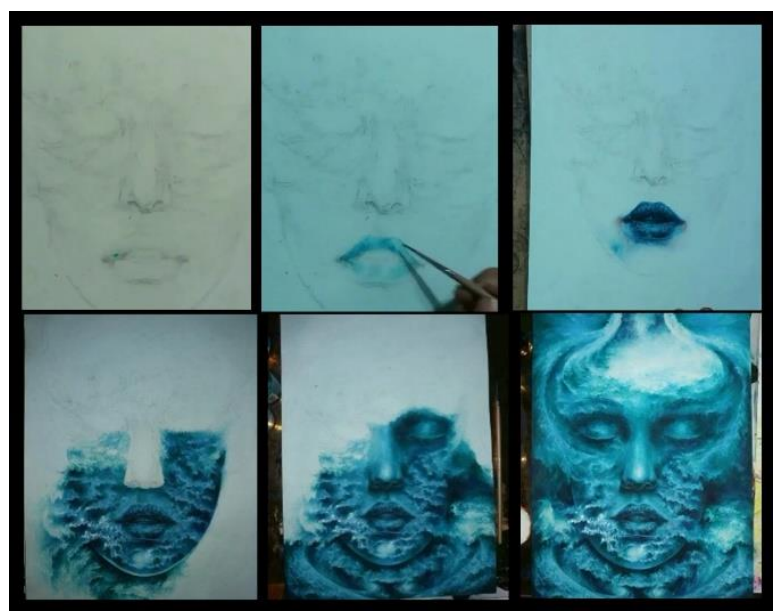

Gambar 2. Tahapan Pembuatan Ilustrasi Cerpen Renjaya Siahaan (Siahaan, 2019)

\section{3). Finishing}

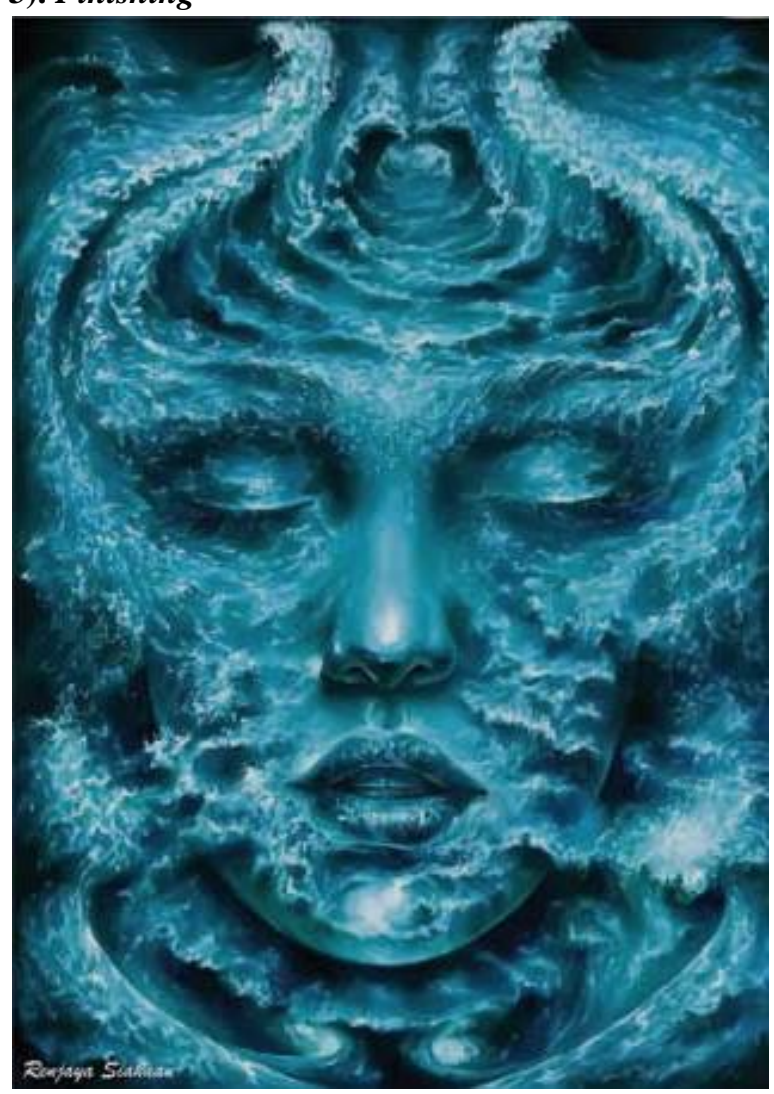

Gambar 3. Hasil Akhir Pembuatan Ilustrasi Cerpen Renjaya Siahaan (Siahaan, 2019)

\section{Pembahasan}

Renjaya Siahaan menggunakan teknik cat air yang bersifat plakat sehingga gambar ilustrasi terlihat kontras dengan warna yang padat. Sehingga penegasan pada bentuk-bentuk yang digambarkan terlihat tegas dan detail. Penggunaan teknik ini merupakan upaya Renjaya Siahaan mengekplorasi media cat air untuk memaksimalkan potensi cat air dalam membuat suatu efek yang diinginkan, dalam hal ini agar tampilan 
warna lebih kontras dan tebal dengan gradasi yang halus.

Sebelum memulai membuat gambar ilustrasi, Renjaya Siahaan terlebih dahulu membaca cerpen yang akan diilustrasikan. Kemudian dilanjutkan dengan perenungan dan observasi terkait objek-objek apa saja yang akan digambarkan untuk mendeskripsikan isi cerpen ke dalam tampilan visual. Kemudian ide yang telah diperoleh langsung dipindahkan ke media kertas dengan mengatur penempatan objek-objek dan pola komposisi yang akan diterapkan terlebih dahulu.

Proses pengerjaan diawali dengan pembuatan sketsa yang tidak terlalu detail, hanya bagian wajah saja yang tampak. Pensil yang digunakan Renjaya Siahaan dalam membuat sketsa yaitu pensil jenis $H B$. Selanjutnya proses pewarnaan diawali dengan pemberian warna transparan terlebih dahulu. Dalam pengerjaannya, biasanya Renjaya Siahaan mewarnai bagian-bagian objek satu persatu terlebih dahulu. Hal ini dilakukan untuk mencampurkan warna lainnya saat cat masih basah sehingga memperoleh efek yang diinginkan. Saat cat masih basah, selanjutnya Renjaya Siahaan menambahkan warna yang lebih gelap dari warna sebelumnya dengan perbandingan air yang lebih sedikit. Efek yang ingin dimunculkan yaitu agar perbatasan warna terang ke warna gelap lebih halus.

Pencampuran warna dilakukan saat permukaan kertas dalam keadaan basah sehingga menghasilkan gradasi warna yang tampak menyatu. Selanjutnya setelah cat kering dilapisi lagi dengan warna yang lebih gelap tanpa dicampur dengan air untuk membentuk warna yang terlihat tegas dan tidak menyatu dengan warna sebelumnya. Dalam mempertimbangan komposisi yang bersifat simetris, pengerjaan ombak bagian kiri dan kanan dikerjakan dalam satu waktu tertentu agar warna tidak tampak putus sehingga tampak gradasi warna yang halus. Dalam tahap ini Renjaya Siahaan tidak lagi mencampur cat dengan air, hal ini agar mendapatkan warna yang benar-benar pekat dan benarbenar gelap untuk memperoleh detail yang kontras karena sifat cat yang menutup lapisan sebelumnya. Sebelum akhirnya gambar ilustrasi dianggap selesai, Renjaya Siahaan selalu mengamati beberapa saat dan memperhatikan bagian mana yang perlu ditambah detailnya.

Kelebihan dari teknik yang diterapkan Renjaya Siahaan ini dibandingkan teknik cat air yang biasanya aquarel yaitu warna bisa ditimpa apabila terjadi kesalahan. Karena apabila menggunakan cat air dengan teknik aquarel akan sulit untuk meminimalisir kesalahan disebabkan lapisan warna pertama akan tetap kelihatan apabila ditimpakan dengan warna setelahnya. Selanjutnya warna yang dihasilkan dengan teknik yang diterapkan Renjaya Siahaan lebih padat, sehingga penegasan pada center of interest akan lebih mudah dimunculkan karena warnanya yang kontras.

\section{KESIMPULAN DAN SARAN \\ 1.Kesimpulan}

Berdasarkan pengamatan tentang teknik ilustrasi cerpen yang telah dilakukan terhadap subjek penelitian, maka beberapa hal yang dapat disimpulkan bahwa proses pembuatan gambar ilustrasi Renjaya Siahaan yang dimulai dengan membaca cerpen yang akan di ilustrasikan, perenungan dan observasi. Selanjutnya setelah ide diperoleh dilanjutkan dengan pembuatan sketsa pada kertas, pemberian warna dasar, menambah kesan gelap terang dan tahap finishing. Penggunaan cat air dengan teknik aquarel lebih efektif dan efisien dalam hal meminimalisir waktu pengerjaan dan penggunaan material dibandingkan dengan teknik yang diterapkan Renjaya Siahaan yang cenderung bersifat plakat. Teknik yang diterapkan Renjaya Siahaan lebih boros cat dan memerlukan lebih banyak waktu dalam proses pengerjaannya. Efek warna yang dihasilkan juga cenderung lebih gelap jika dibandingkan dengan teknik aquarel yang biasanya lebih cerah.

\section{Saran}

Berdasarkan kesimpulan dari hasil penelitian, maka teknik merupakan suatu hal yang utama dikuasai Ilustrator dalam mengolah ide menjadi sebuah gambar ilustrasi. Teknik diharapkan pula menjadi ciri khas tersendiri untuk membedakan satu Ilustrator dengan Ilustrator lainnya. Bagi kalangan akademisi beserta kalangan seniman, selain jadi bahan pembelajaran dalam mengenal teori cat air dan diharapkan pula agar memiliki keberanian dalam mengeksplorasi penggunaan alat dan media yang digunakan dalam berkarya. Sehingga diperoleh ciri khas dalam setiap karya yang diciptakan. Juga tidak menutup kemungkinan bagi masyarakat agar tidak menutup diri terhadap karya seni khususnya gambar ilustrasi. Karena gambar ilustrasi sudah banyak media pengaplikasiannya, contohnya pada tembok untuk tujuan menghias dan memberi pesan.

\section{DAFTAR RUJUKAN}

Halawa, W. E., Triyanto, R., Budiwiwaramulja, D., \& Azis, A. C. K. (2020). Analisis Gambar Ilustrasi Hombo Batu Nias Gunungsitoli. Gorga: Jurnal Seni Rupa, 9(1), 193-203. 


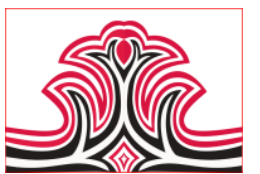

Gorga : Jurnal Seni Rupa

Volume 10 Nomor 01 Januari-Juni 2021

p-ISSN: 2301-5942 | e-ISSN: 2580-2380

Kusrianto, Adi. (2007). Pengantar Desain Komunikasi

Visual. Yogyakarta: Andi.

Maharsi, Indiria. (2016). Ilustrasi. Yogyakarta: ISI

Yogyakarta.

Priyatni, Endah Tri. (2010). Membaca Sastra dengan Ancangan Literasi Kritis. Jakarta: Bumi Aksara.

Said, Abdul Aziz dan Arifin, Irfan. (2016). DasarDasar Melukis Cat Air. Jurnal DKV Fakultas Seni dan Desain UNM, 3(2), 9-18.

Salam, Sofyan. (2017). Seni Ilustrasi. Makassar: Badan Penerbit UNM.

Sembiring, Dermawan. (2014). Wawasan Seni. Medan: Unimed Press.

Siahaan, R. (2019). "Hasil Karya Ilustrasi”. Hasil Dokumentasi Pribadi: 18 November 2019, Mieko Art School. 